\title{
Is There a Relationship between High IQ Scores and Positive Life Outcomes? A Critical Review
}

\author{
Chi-Fai Lo ${ }^{1,2,3}$ \\ ${ }^{1}$ Institute of Theoretical Physics and Department of Physics, The Chinese University of Hong Kong, \\ Hong Kong, China \\ ${ }^{2}$ Department of Psychology, Sociology and Politics, Sheffield Hallam University, Sheffield, United Kingdom \\ ${ }^{3}$ Social and Human Sciences Section, SCOPE, City University of Hong Kong, Hong Kong, China \\ Email: edcflo@gmail.com
}

How to cite this paper: Lo, C.-F. (2017). Is There a Relationship between High IQ Scores and Positive Life Outcomes? A Critical Review. Psychology, 8, 627-635. https://doi.org/10.4236/psych.2017.84040

Received: February 2, 2017

Accepted: March 25, 2017

Published: March 28, 2017

Copyright (C) 2017 by authors and Scientific Research Publishing Inc. This work is licensed under the Creative Commons Attribution International License (CC BY 4.0).

http://creativecommons.org/licenses/by/4.0/

\begin{abstract}
This review paper attempts to critically discuss the relationship between high IQ scores and positive life outcomes with reference to research findings. Particularly, three major questions are examined in detail, i.e. 1) How significant is the correlation between IQ scores and socioeconomic success? 2) Does the predictive power of IQ scores outperform other variables such as parental socioeconomic status or school grades? 3) Are there any age-related or historical changes in the relationship between IQ scores and socioeconomic success? It is found that although researchers find some consensus in their empirical findings, yet they disagree strongly about others, too. This may be attributed to the fact that well-controlled experiments in intelligence research are usually not possible and thus conclusions are based upon mere correlations or the results of necessarily ill-controlled natural experiments. Accordingly, not all conclusions are fully supported by the evidence and generally accepted by the research community. To resolve the controversy, perhaps improving the research methodology and skills is of top priority.
\end{abstract}

\section{Keywords}

High IQ Scores, Intelligence, Positive Life Outcomes, Socioeconomic Success

\section{Introduction}

Today "an individual with a high IQ" has become a synonym for "genius" and it is commonly believed that the gifted individual is destined for greater success in life. Thus, not only are parents eager to have their children to take IQ tests which are used in primary and secondary schools to sort students into streams, but also employers believe that hiring people based upon intelligence leads to marked 
improvements in job performance (i.e. "select on intelligence"). IQ scores are also frequently employed as a gauge for the allocation of scarce developmental resources in various institutions. Nevertheless, is it just a myth that having a high IQ predicts greater success in life?

Psychologists have long been interested in investigating whether there is a relationship between high IQ scores and positive life outcomes or not. Over the past century, the scientific research on the topic has established one of the most robust social science findings of the $20^{\text {th }}$ century that IQ scores predict a broad range of life outcomes such as academic performance, years of education, physical health and longevity, job performance, etc. (Gottfredson, 2004; Hogan, 2005; Jensen, 1998; Judge, Colbert, \& Ilies, 2004; Neisser et al., 1996; Roberts et al., 2007; Sternberg, Grigorenko, \& Bundy, 2001). More specifically, people with higher IQ scores are better educated, hold more prestigious occupations, and can earn higher incomes than people with lower scores. Despite the predictive power of IQ scores for socioeconomic success, as measured by the educational level, occupational prestige, and income of an individual in adulthood, several major questions still remain unanswered and need further investigations. First, how significant is the correlation between IQ scores and socioeconomic success? Is it large enough to be of any practical importance? Second, does the predictive power of IQ scores outperform other variables such as parental socioeconomic status or school grades? Third, are there any age-related or historical changes in the relationship between IQ scores and socioeconomic success? Accordingly, it is the aim of this paper to critically discuss these questions with reference to research findings.

The outline of this paper is as follows. In the next section a critical review of previous research using the static approach to investigate the positive association between the IQ scores and socioeconomic success is presented. Despite identifying the main effects of the three predictors of socioeconomic success, namely IQ scores, parental socioeconomic status and academic performance, the static approach lacks the information about the processes by which these predictors affect success. Hence, in the section 3, previous research using the alternative approach, i.e. the dynamic approach, is critically examined. Finally, the paper concludes in the last section.

\section{Static Approach}

To address the three major questions, the longitudinal research on the positive association between IQ scores and socioeconomic success is needed because only longitudinal research design is capable of examining the possible causal impact of IQ scores on success. The most well-known longitudinal study was done by Herrnstein \& Murray (1994) who published the controversial book "The Bell Curve". After analyzing a representative longitudinal data set from the United States, Herrnstein and Murray found that IQ scores outperform parental socioeconomic status in predicting several desirable outcomes. A similar finding was also reported by Saunders who analyzed a representative longitudinal data 
set from Great Britain and observed that IQ scores are a better predictor of occupational success than parental socioeconomic status (Bond \& Saunders, 1999; Saunders, 1997, 2002). However, both studies were severely criticized for either underestimating the importance of parental socioeconomic status or overestimating the importance of IQ scores (Fisher et al., 1996; Hauser \& Huang, 1997; Breen \& Goldthorpe, 1999, 2001). Accordingly, more comprehensive meta-analyses of the longitudinal research are desirable.

Bowles, Gintis, \& Osborne (2001) conducted the first comprehensive metaanalysis of the relationship between IQ scores and socioeconomic success using income as a measure of success. Compiling 65 estimates from 24 studies, they examined the relationship and determined the mean standardized regression coefficient of IQ scores on income as 0.15 . In addition, neither there is any time trend in the size of the coefficients between the years 1960 and 1995 nor the age of the sample at the time of IQ testing has any effect on the results. In spite of being avaluable contribution, the meta-analysis of Bowles, Gintis, \& Osborne (2001) suffers from several shortcomings (Strenze, 2007):

1) Only one measure of success, i.e. income, was considered, with both education and occupation being neglected.

2) The meta-analytic estimate of the mean standardized regression coefficient was not derived from zero-order correlations but from regression equations that included several other predictors.

3) The meta-analysis was not based upon independent samples.

Another similar meta-analysis was reported by Ng, Eby, Sorensen, \& Feldman (2005) who assembled 8 studies and obtained an average correlation of 0.27 between IQ scores and salary from zero-order correlations and independent samples. Nevertheless, both meta-analyses failed to separate cross-sectional and longitudinal studies.

In view of the shortcomings of these two meta-analyses, Strenze (2007) conducted a more thorough meta-analysis of the relationship between IQ scores and socioeconomic success using education, occupation and income as measures of success. Both parental socioeconomic status and academic performance (school grades) are also included as predictors of success in order to better evaluate the predictive power of intelligence (IQ scores). Excluding the samples that the participants were too old (over 18) at the time of IQ testing or too young (below 30) at the measurement of success, the overall correlations were found to be 0.56 (between intelligence and education), 0.45 (between intelligence and occupation) and 0.23 (between intelligence and income). While the correlations with education and occupation are of substantial magnitude according to the usual standards of social science (Cohen, 1998), the correlation with income is considerably lower, being about the average of the previous meta-analytic estimates (Bowles et al., 2001; Ng et al., 2005). Removing the constraints on age resulted in slight reduction of the correlations only: 0.56 (education), 0.43 (occupation) and 0.20 (income). In addition, Strenze (2007) showed that both parental socioeconomic status and school grades are positively related to career success but their 
predictive power is not so strong as intelligence. These results disprove the claim that the correlation between intelligence and success is a mere byproduct of the causal effect of parental socioeconomic status or school grades (Bowles \& Gintis, 1976; Fisher et al., 1996; McClelland, 1973), and confirm that intelligence is an independent causal force among the predictors of success. Hence, intelligence is a powerful predictor of socioeconomic success but not an overwhelmingly better predictor than parental socioeconomic status or academic performance.

In the meta-analysis of Strenze (2007) a number of moderator analyses of the correlation between intelligence and success were performed to investigate the effects of three moderator variables, namely age at testing, age at success, and year of measurement of success. Analyses of age at testing clearly indicates that the IQ scores of older individuals are better predictors of success than the scores of younger individuals, confirming the gravitational hypothesis about intellectual differences cumulating throughout life course. With regard to age at success, correlations with occupation and income increase as individuals grow older but the IQ-education correlation takes an opposite path. The negative impact of age at success on the IQ-education correlation provides some support for the declining validity hypothesis of diminishing significance of intellectual differences with age. There is, however, essentially no effect of year of measurement of success on the intelligence-success correlation. Furthermore, there is little evidence of any historical trend in the relationship between intelligence and success.

Despite the extensiveness of Strenze's (2007) meta-analysis, the analysis did not control for the correlation between parental socioeconomic status and intelligence so that their individual influences on socioeconomic success could not be disentangled. In order to disentangle the nexus between the two predictors of success, Von Stumm, Macintyre, Batty, Clark, \& Deary (2010) conducted an investigation of the status attainment by midlife in a large birth cohort of 6281 Scottish men who were assessed in childhood (at the age of 11 years) and again at midlife (between the ages of 46 and 51 years). The results confirmed that after controlling for the correlation between social class of origin and childhood intelligence, not only social status attainment is influenced to a considerably greater extent by childhood intelligence than by social class of origin but also the effects of intelligence on educational attainment are twice as strong as those of social class of origin. It was also found that education partially mediates the effects of childhood intelligence and social class of origin.

The aforementioned longitudinal studies have taken the so-called static approach to study the main effects of intelligence, parental socioeconomic status and academic performance on socioeconomic success. In this static approach the indicators of success are regressed on the three predictors and their effects are compared. There is very little criticism about the principles of this method and most debates centre primarily on the accuracy of measurement of the predictors of success. Hence, the static approach mainly provides the relative impact of the three predictors on socioeconomic success but it lacks the information about the processes by which these predictors affect success. 


\section{Dynamic Approach}

Using the sample of an educationally homogeneous group of participants who had completed just 12 years of education, Ganzach (2011) applied an alternative approach called the dynamic approach to examine the way socioeconomic background and intelligence affect the setting of the initial wages and the subsequent increases in wages. The sample data were taken from the National Longitudinal Survey of Youth, conducted with a probability sample of 12,686 Americans who were born between 1957 and 1964. In spite of some variability in age in the sample, the basic sampling was of a specific cohort. This variability allows us to examine the dynamic effects of socioeconomic background and intelligence in both a cross-sectional design and a longitudinal design. In the study the participants were first interviewed in 1979, followed by annual interviews till 1994. Then the participants were interviewed bi-annually over the period between 1995 and 2000.

It was observed that socioeconomic background affects wages solely by its effect on entry pay whereas intelligence affects how wages develop and change over time. The effect of intelligence on entry pay is also weaker than the effect of socioeconomic background. Thus, the two predictors of success play different roles in the dynamic of job-market success, and intelligence is the driving force of individuals' progress in the job market. These results are consistent with previous empirical findings:

1) Social networking via friends and relatives is crucial at entry to the job market because they may supply useful information regarding job openings and interview skills (Grieco, 1987; Aguilera, 2002).

2) The gravitational influence of intelligence on job-market mobility increases with age because people take time to gravitate towards their cognitive abilityappropriate jobs with higherpay (McCormick, DeNisi, \& Shaw, 1979; McCormick, Jeanneret, \& Mecham, 1972; Gottfredson, 2003; Strenze, 2007).

Moreover, given the differences in the effect of intelligence and socioeconomic background on wages, the results demonstrated that the relative weight of the two predictors of success varies with age. In fact, the predictors of success affect the wage dynamics in two different ways, namely stable influence and increasing influence. Stable influence is characterized by a constant gap between the wage trajectories associated with low and high levels of a predictor, but for increasing influence the gap increases with time. Ganzach (2011) suggested that increasing influence is more likely to describe the effect of intelligence on wage trajectories whereas stable influence can better describe the effect of socioeconomic background. Accordingly, different conclusions about the relative impact of socioeconomic background and intelligence would emerge depending upon the time the analysis was made.

Recently another dynamic study was performed by Sorjonen, Hemmingsson, Deary, \& Melin (2015) with an age-homogeneous, population-representative sample of 49,246 Swedish men. The objective of their study is of twofold:

1) To examine how occupational and income trajectories are affected by intel- 
ligence, socioeconomic background and level of education; and

2) To examine if, and how much, level of education mediates the effects that intelligence and socioeconomic background might have on occupational and income trajectories.

The empirical results showed that intelligence and socioeconomic background are both positively correlated with occupational and income trajectories, with socioeconomic background having a weaker effect. That is, occupational position and income grow more steeply with age among those with high intelligence and a more advantageous socioeconomic background. However, the growth is so fast that a ceiling effect in the attainment of occupational position and income is reached quite soon. It was also observed that the effects of intelligence and socioeconomic background on occupational and income trajectories are to a large extent mediated by level of education.

Furthermore, von Stumm \& Plomin (2015) investigated the impact of parental socioeconomic status on developmental change in intelligence using a large sample of 14,853 twins (i.e. 7426 complete pairs, including 2564 monozygotic twin pairs and 4862 dizygotic twin pairs, of which 2375 were of opposite sex) from the Twins Early Development Study in UK. The twins were assessed 9 times on IQ between the ages of 2 and 16 years. The results showed that parental socioeconomic status is significantly correlated with intelligence growth factors: higher parental socioeconomic status is related both to a higher starting point of intelligence in infancy and to greater gains in intelligence over time. Specifically, children from more disadvantaged families scored on average 6 IQ points lower at age 2 than those from more privileged homes, and by the age of 16 the IQ gap almost tripled.

\section{Discussion}

All in all, extensive research shows that IQ scores can play a critical role in determining positive life outcomes like success in academic performance from elementary school through college, job performance, and occupational status. These results seem to confirm the validity of IQ tests to measure intellectual abilities which lead towards the types of success that are valued in Western cultures. In other words, IQ assessment may thus become destiny.

Nevertheless, Byington \& Felps (2010) argued that institutionalized practices enable individuals with high IQ to develop better capabilities and the observed relationship between IQ scores and job performance is confounded by the fact that opportunities have been allocated based upon IQ scores. That is, those with higher IQ scores are likely to have had more success experiences in school, become more motivated to study, develop an achievement orientation, and become optimistic about their chances of doing well, whereas those with low scores may experience just the opposite, e.g. getting "trapped" into schools or programs that are inferior. Likewise, many researchers still argue that other variables such as family background, socioeconomic status, educational experiences, motivation, willingness to work hard, being committed to goals, creativity and emotional 
maturity are also strongly linked to success in life. For instance, Bergman, Ferrer-Wreder, \& Zukauskiene (2015) conducted a study of the educational and vocational careers of a sample of 1326 Swedish adolescents with below average IQ, who were born in 1955 and followed from early adolescence to midlife, and found that, after controlling for confounders, the only significant predictor of career outcomes within the low IQ group was educational aspirations. In other words, adolescents with below average IQ could achieve success in their educational and vocational career if they are highly motivated.

To wind up, we must admit that IQ tests are still one of the most controversial products in psychology. Although researchers find some consensus in their empirical findings, yet they disagree strongly about others, too. This may be attributed to the fact that well-controlled experiments in intelligence research are usually not possible and thus conclusions are based upon mere correlations or the results of necessarily ill-controlled natural experiments. As a result, not all conclusions are fully supported by the evidence and generally accepted by the research community. To resolve the controversy, perhaps improving the research methodology and skills is of the top priority.

\section{Acknowledgements}

The author would like to thank both Dr. Jonathan Yeung and Dr. Sue JamisonPowell for their useful comments and suggestions.

\section{References}

Aguilera, M. B. (2002). The Impact of Social Capital on Labor Force Participation: Evidence from 2000 Social Capital Benchmark Survey. Social Science Quarterly, 83, 853874. https://doi.org/10.1111/1540-6237.00118

Bergman, L. R., Ferrer-Wreder, L., \& Zukauskiene, R. (2015). Career Outcomes of Adolescents with Below Average IQ: Who Succeeded against the Odds? Intelligence, 52, 917.

Bond, R., \& Saunders, P. (1999). Routes of Success: Influences on the Occupational Attainment of Young British Males. British Journal of Sociology, 50, 217-252. https://doi.org/10.1111/j.1468-4446.1999.00217.x

Bowles, S., \& Gintis, H. (1976). Schooling in Capitalist America: Educational Reform and the Contradictions of Economic Life. London: Routledge and Paul Kegan.

Bowles, S., Gintis, H., \& Osborne, M. (2001). The Determinants of Earnings: A Behavioral Approach. Journal of Economic Literature, 39, 1137-1176. https://doi.org/10.1257/jel.39.4.1137

Breen, R., \& Goldthorpe, J. H. (1999). Class Inequality and Meritocracy: A Critique of Saunders and an Alternative Analysis. British Journal of Sociology, 50, 1-27. https://doi.org/10.1111/j.1468-4446.1999.00001.x

Breen, R., \& Goldthorpe, J. H. (2001). Class, Mobility and Merit: The Experience of Two British Birth Cohorts. European Sociological Review, 17, 81-101. https://doi.org/10.1093/esr/17.2.81

Byington, E., \& Felps, W. (2010). Why Do IQ Scores Predict Job Performance? An Alternative, Sociological Explanation. Research in Organizational Behavior, 30, 175-202.

Cohen, J. (1988). Statistical Power Analysis for the Behavioral Sciences (2nd ed.). Mah- 
wah, NJ: Lawrence Erlbaum Associates.

Fisher, C. S., Hout, M., Jankowski, M. S., Lucas, S. R., Swidler, A., \& Voss, K. (1996). Inequality by Design: Cracking the Bell Curve Myth. Princeton, NJ: Princeton University Press.

Ganzach, Y. (2011). A Dynamic Analysis of the Effects of Intelligence and Socioeconomic Background on Job-Market Success. Intelligence, 39, 120-129.

Gottfredson, L. S. (2003). G, Jobs and Life. In H. Nyborg (Ed.), The Scientific Study of General Intelligence: Tribute to Arthur R. Jensen (pp. 293-342). Amsterdam: Pergamon.

Gottfredson, L. S. (2004). Intelligence: Is It the Epidemiologists' Elusive "Fundamental Cause" of Social Class Inequalities in Health? Journal of Personality and Social Psychology, 86, 174-199. https://doi.org/10.1037/0022-3514.86.1.174

Grieco, M. (1987). Keeping it in the Family: Social Networks and Employment Chance. London: Tavistock Publications.

Hauser, R. M., \& Huang, M. H. (1997). Verbal Ability and Socioeconomic Success: A Trend Analysis. Social Science Research, 26, 331-376. https://doi.org/10.1006/ssre.1997.0604

Herrnstein, R. J., \& Murray, C. (1994). The Bell Curve: Intelligence and Class Structure in American Life. New York, NJ: Free Press.

Hogan, R. (2005). In Defense of Personality Measurement: New Wine for Old Whiners. Human Performance, 18, 331-341. https://doi.org/10.1207/s15327043hup1804_1

Jensen, A. R. (1998). The G Factor: The Science of Mental Ability. Westport, CT: Praeger/Greenwood.

Judge, T. A., Colbert, A. E., \& Ilies, R. (2004). Intelligence and Leadership: A Quantitative Review and Test of Theoretical Propositions. Journal of Applied Psychology, 89, 542552. https://doi.org/10.1037/0021-9010.89.3.542

McClelland, D. C. (1973). Testing for Competence Rather than for Intelligence. American Psychologist, 28, 1-14. https://doi.org/10.1037/h0034092

McCormick, E. J., DeNisi, A. S., \& Shaw, J. B. (1979). Use of the Position Analysis Questionnaire for Establishing the Job Component Validity of Tests. Journal of Applied Psychology, 64, 51-56. https://doi.org/10.1037/0021-9010.64.1.51

McCormick, E. J., Jeanneret, P. R., \& Mecham, R. C. (1972). A Study of Job Characteristics and Job Dimensions as Based on the Position Analysis Questionnaire (PAQ). Journal of Applied Psychology, 56, 347-368. https://doi.org/10.1037/h0033099

Neisser, U., Boodoo, G., Bouchard Jr., T. J., Boykin, A. W., Brody, N., Ceci, S. J., Halpern, D. F., Loehlin, J. C., Perloff, R., Sternberg, R. J., \& Urbina, S. (1996). Intelligence: Knowns and Unknowns. American Psychologist, 51, 77-101. https://doi.org/10.1037/0003-066X.51.2.77

Ng, T. W. H., Eby, L. T., Sorensen, K. L., \& Feldman, D. C. (2005). Predictors of Objective and Subjective Career Success: A Meta-Analysis. Personnel Psychology, 58, 367-408. https://doi.org/10.1111/j.1744-6570.2005.00515.x

Roberts, B. W., Kuncel, N. R., Shiner, R., Caspi, A., \& Goldberg, L. R. (2007). The Power of Personality: The Comparative Validity of Personality Traits, Socioeconomic Status, and Cognitive Ability for Predicting Important Life Outcomes. Perspectives on Psychological Science, 2, 313-345. https://doi.org/10.1111/j.1745-6916.2007.00047.x

Saunders, P. (1997). Social Mobility in Britain: An Empirical Evaluation of Two Competing Explanations. Sociology, 31, 261-288.

https://doi.org/10.1177/0038038597031002005 
Saunders, P. (2002). Reflections on the Meritocracy Debate in Britain: A Response to Richard Breen and John Goldthorpe. British Journal of Sociology, 53, 559-574. https://doi.org/10.1080/0007131022000021489

Sorjonen, K., Hemmingsson, T., Deary, I. J., \&Melin, B. (2015). Mediation of the Gravitational Influence of Intelligence on Socio-Economic Outcomes. Intelligence, 53, 8-15.

Sternberg, R. J., Grigorenko, E. L., \& Bundy, D. A. (2001). The Predictive Value of IQ. Merrill-Palmer Quarterly, 47, 1-141. https://doi.org/10.1353/mpq.2001.0005

Strenze, T. (2007). Intelligence and Socioeconomic Success: A Meta-Analytic Review of Longitudinal Research. Intelligence, 35, 401-426.

Von Stumm, S., Macintyre, S., Batty, D. G., Clark, H., \& Deary, I. J. (2010). Intelligence, Social Class of Origin, Childhood Behavior Disturbance and Education as Predictors of Status Attainment in Midlife in Men: The Aberdeen Children of the 1950s Study. Intelligence, 38, 202-211.

Von Stumm, S., \& Plomin, R. (2015). Socioeconomic Status and the Growth of Intelligence from Infancy through Adolescence. Intelligence, 48, 30-36.

Submit or recommend next manuscript to SCIRP and we will provide best service for you:

Accepting pre-submission inquiries through Email, Facebook, LinkedIn, Twitter, etc. A wide selection of journals (inclusive of 9 subjects, more than 200 journals)

Providing 24-hour high-quality service

User-friendly online submission system

Fair and swift peer-review system

Efficient typesetting and proofreading procedure

Display of the result of downloads and visits, as well as the number of cited articles

Maximum dissemination of your research work

Submit your manuscript at: http://papersubmission.scirp.org/

Or contact psych@scirp.org 